\title{
Probability model of forward birth interval and its application
}

\author{
Ajay Shankar Singh \\ Department of AEM, University of Swaziland, Luyengo campus, Luyengo M205, Swaziland
}

Email address:

singhas64@hotmail.com

To cite this article:

Ajay Shankar Singh. Probability Model of Forward Birth Interval and Its Application. American Journal of Theoretical and Applied Statistics. Vol. 3, No. 6, 2014, pp. 223-227. doi: 10.11648/j.ajtas.20140306.18

\begin{abstract}
In renewal theory approach, it is well known that the limiting forms of the probability density function of backward recurrence time and forward recurrence time which are similar to open birth interval and forward birth interval are identical on the assumption that the renewal densities do not change over time. The forward birth interval defined as the time between the survey date and the date of next birth posterior to the survey date. Forward birth interval is a good index for current change in fertility behavior. The present model has been derived on the assumption that females are not exposed to the risk of conception immediately after the termination of Post-Partum Amenorrhea (PPA). However they may be exposed to the risk of conception at different point of time after the termination of PPA because of some socio-cultural factors or contraceptive practices. In this probability model for forward birth interval regardless of parity assuming that renewal density does not change over time and females are exposed to the risk of conception at different point of time. In this model, fecundability $(\lambda)$ and the duration of time from the point of termination of PPA to the state of exposure as random variable $(\mu)$ which follows exponential distribution. The maximum likelihood estimation technique has been used for the estimation of parameters $\lambda$ and $\mu$ through derived model. The estimated values of $\lambda$ and $\mu$ are 1.1051 and 2.841 respectively. The variance of estimated $\lambda$ and $\mu$ are 0.067 and 0.79 respectively. The co-variance in between estimated $\lambda$ and $\mu$ is -0.026 . With these estimates the expected frequencies for the distribution and $\chi^{2}=0.6057$ is highly significant. Thus, the derived probability model explains the fertility behavior of observed data satisfactorily well.
\end{abstract}

Keywords: Fecundability, Birth Interval, Post Partum Amenorrhea, Maximum Likelihood Estimation, Contraceptive Practices

\section{Introduction}

Fertility, as the positive force, is principally responsible for the rapid growth of population. Fertility behavior is usually influenced by the action and interaction of a number of complex factors. It is now almost established that traditional socio-cultural practices which are a part of our social fabric have a very vital bearing on our social life and affect fertility variations in a complex manner. The social scientists and demographers have given high priority to thorough understanding of the differentials and determinants of fertility through various mathematical and statistical modeling techniques. Mathematical models are very appropriate tools and widely used for better understanding of the complex human reproduction process. The statistical models for complex fertility process play an important role in drawing inferences from the observed data and also providing the estimates of the fertility parameters relating to the human reproduction process. In the derived models so far, adequate attention has not been given to the prevalent socio-cultural and contraceptive practices. Needless to say that these factors are regulates and determine the coital pattern and abstinence after marriage or child birth. Moreover, they also affect fecundability and non susceptible periods. Thus, the present existing model may not be appropriate to describe the real fertility data.

The importance of differentials in fertility has been reported by a number of researchers and demographers [1-3]. Mathematical models are very appropriate tools and are widely used for better understanding of the phenomenon of the complex process of human fertility behavior. In other words, these models are useful in describing the action and interaction or inter relationship among various factors as well as for predicting the change in fertility behavior. Gini (1924) was the first in this area to initiate research in model 
construction, by introducing the concept of fecundability and analyzed the data on first birth interval to estimate the fecundability on the assumption that fecundability remains constant among the females before the first conception [4]. Sheps (1964) and Singh(1966) and others have given detailed discussions on the variables to be included in the model [5, 6].In the last decades considerable attention has been given to analyze the data on closed birth interval or interval between two successive live births. The main importance of the closed birth interval is due to inclusion of amenorrhoeic period, temporary separation due to social taboos or use of contraceptives. Bhattacharya et al. (1988) have derived a probability model to describe the length of interval between successive live births by taking different parametric form of risk function and one to one correspondence between conception and a live birth [7]. Singh (1989) derived time dependent model for inter live birth interval with finite exposure period by taking into account intrauterine mortality and a distribution for the non- susceptible period [8]. Singh (1992) derived analytical models for human fertility behavior and their applications with the consideration of socio cultural factors [9]. Mturi (1997) studied the determinants of birth interval s among non contracepting Tanzanian women [10]. Rao (2006) studied correlates of inter-birth interval and their implications of optional birth spacing strategies in Mozambique [11]. Recently, Singh et al. (2011) discussed the demographic and socio-economic determinants of birth interval dynamics [12]. Yadav et al. (2013) estimate the parity progression ratios from open and closed birth interval data [13]. Singh (2014) derive the probability model on close birth interval and estimate the fecundability [14].

Some of the main biological factors:

Fecundability: It is defined as the probability that a non pregnant fecund woman will conceive in one unit of the time of the exposure to the risk of conception. The unit is taken as one month which is the length of a menstrual cycle.

Sterility: A female is said to be sterile if conception is impossible physiologically.

Foetal Wastage: A conception may not always result in a live birth. The outcome of the corresponding pregnancy may end in a spontaneous foetal death, an induced abortion and still birth.

Non Susceptible Period: This is the sum of the two parts; first, gestation period and second the interval after its termination and before the resumption of the ovulation, which is the known as post partum amenorrhea (PPA) period.

There are two broad categories of the fertility model. First, the model which deals with the utilization of the data on point events like as conception, live births to women in a specified period of time. The second type of models utilizes the data on interval between the consecutive events. Both type of models have own usefulness as well as limitations. The present paper is associated with second type of model. Various types of birth intervals discussed so far in the literature are:

First Birth Interval: The interval between marriage to first live birth. This interval gives the recent marital fertility performance.

Closed Birth Interval: The interval between two successive live births. This gives the actual fertility performance in between two successive birth as well as impact of PPA and temporary separation and impact of family planning.

Open Birth Interval: The interval between the date of birth of last child to the date of the survey. This provides the latest fertility performance.

Straddling Birth Interval: Any closed birth interval that straddles the survey date.

Interior Birth Interval: A closed birth interval lying during a specified marriage duration or between two survey dates.

Forward Birth Interval: The interval between survey date and the date of next live birth posterior to the survey date.

In renewal theory, it is well known that the limiting forms of the probability density functions of backward recurrence time and forward recurrence time which are similar to open birth interval are identical on the assumption that the renewal densities do not changeover time [15, 16]. Obviously, if renewal density change after some time (say survey point), the distribution of forward birth interval and open birth interval will not be identical, Pandey (1981) has derived the forward birth interval under the assumption that a family planning programme has been introduced in the population at the survey point and has obtained the expressions for mean and variance for different situations [17]. Singh and Singh, (1991) derived generalized model for forward birth interval and estimate the fecundability [18].

In this paper, stochastic model on forward birth interval regardless of parity assuming that renewal density does not change over time and females are exposed to the risk of conception at different points of time after the termination of PPA.

\section{Model}

A cohort of $\mathrm{N}$ women were observed for a period of time say $\mathrm{T}_{1}$ since a time point $\mathrm{T}$ distant enough from marriage for their first birth on or before $T_{1}$. The distribution of the forward birth interval for such females derived under some simplified assumptions [14].

1. The female has led married life throughout the period of observation.

2. Let $h$ be the constant duration of non- susceptibility associated with each live birth comprised of gestation and the period of PPA.

3. The duration of non- susceptibility after the termination of PPA which is caused by some social factors or use of contraceptive practices be a non-negative random variable. Let the female after termination of her PPA will enter into susceptible state in a small interval ( $\mathrm{t}$, $\mathrm{t}+\Delta \mathrm{t})$ is $\mu \Delta \mathrm{t}+0 \Delta \mathrm{t} ; \mu>0, \Delta \mathrm{t}>0$ and $\mathrm{t}>0$

4. Let the female who is susceptible to conception at time $t$ will conceive in a small interval $(\mathrm{t}, \mathrm{t}+\Delta \mathrm{t})$ is $\lambda \Delta \mathrm{t}+0 \Delta \mathrm{t}$; $\lambda>0, \Delta \mathrm{t}>0$ and $\mathrm{t}>0$

5 . Let each conception results in to a live birth.

If the marital duration of the female is large enough the probability density function of forward birth interval which 
are similar to open birth interval regardless of parity is given $[15,16]$.

$$
\mathrm{W}(\mathrm{t})=[1-\mathrm{F}(\mathrm{t})] / \mu^{*}
$$

Where, $\mathrm{F}(\mathrm{t})$ and $\mu^{*}$ are the distribution function and mean length of the waiting time between two consecutive live births respectively. The expressions for $\mathrm{F}(\mathrm{t})$ and $\mu^{*}$ under the assumption are;

$$
\mathrm{F}(\mathrm{t})=1-\left[\{1 /(\mu-\lambda)\}\left\{\mu \mathrm{e}^{-\lambda(\mathrm{t}-\mathrm{h})}-\lambda \mathrm{e}^{-\mu(\mathrm{t}-\mathrm{h})}\right] \text { if } \mathrm{t}>\mathrm{h}\right.
$$

$\mathrm{F}(\mathrm{t})=0$ otherwise

$$
\mu^{*}=h+1 / \mu+1 / \lambda
$$

Substituting the value of $F(t)$ and $\mu^{*}$ from (2) and (3) in the probability density function of forward birth interval (1)

$$
\begin{gathered}
\mathrm{W}(\mathrm{t})=1 /[\mathrm{h}+1 / \mu+1 / \lambda] ; 0<\mathrm{t}<\mathrm{h} \\
=\left[\{1 /(\mu-\lambda)\}\left\{\mu \mathrm{e}^{-\lambda(\mathrm{t}-\mathrm{h})}-\lambda \mathrm{e}^{-\mu(\mathrm{t}-\mathrm{h})}\right] /[\mathrm{h}+1 / \mu+1 / \lambda] ; \mathrm{t}>\mathrm{h}\right.
\end{gathered}
$$

and the corresponding distribution function is

$$
\begin{gathered}
\mathrm{W}(\mathrm{t})=\mathrm{t} /[\mathrm{h}+1 / \mu+1 / \lambda] ; 0<\mathrm{t} \leq \mathrm{h} \\
=[\mathrm{h}+1 / \mu+1 / \lambda-\{\mu /(\mu-\lambda)\} \mathrm{e}-\lambda(\mathrm{t}-\mathrm{h})-\{\lambda /(\mu-\lambda)\} \mathrm{e}-\mu(\mathrm{t}-\mathrm{h})] /(\mathrm{h}+1 / \mu+1 / \lambda) ; \mathrm{t}>\mathrm{h}
\end{gathered}
$$

The distribution derived above model implicitly continuance of observations for a long time after $\mathrm{T}$ which may not always feasible. Thus, if the study is terminated after time $\mathrm{T}_{1}$ from $\mathrm{T}$, the modified probability density function and corresponding distribution function will be derived as,

$$
\begin{gathered}
\mathrm{W}_{\mathrm{T} 1}{ }^{*}(\mathrm{t})=\mathrm{w}(\mathrm{t}) / \mathrm{W}(\mathrm{T} 1) \\
\mathrm{W}\left(\mathrm{T}_{1}\right)=\int[1-\mathrm{F}(\mathrm{t})] / \mu^{*} \mathrm{dt} \text { Range } 0 \text { to } \mathrm{T}_{1}
\end{gathered}
$$

$$
\begin{gathered}
=\left[\mathrm{h}_{\mathrm{v}}+1 / \mu+1 / \lambda-\{\mu /(\mu-\lambda)\} \mathrm{e}_{1}^{-\lambda(\mathrm{T}-\mathrm{h})}-\{\lambda /(\mu-\lambda)\} \mathrm{e}_{1}^{-\mu\left(\mathrm{T}_{1}-\mathrm{h}\right)}\right] /(\mathrm{h}+1 / \mu+1 / \lambda) ; \mathrm{t}>\mathrm{h} \\
\mathrm{w}_{\mathrm{T} 1} *(\mathrm{t})=1 /\left[\mathrm{h}_{\mathrm{v}}+1 / \mu+1 / \lambda-\{\mu /(\mu-\lambda)\} \mathrm{e}_{1}^{-\lambda\left(\mathrm{T}_{1}-\mathrm{h}\right)}-\{\lambda /(\mu-\lambda)\} \mathrm{e}_{1}^{-\mu\left(\mathrm{T}_{1}-\mathrm{h}\right)}\right] ; 0<\mathrm{t} \leq \mathrm{h} \\
=\left[\{\mu /(\mu-\lambda)\} \mathrm{e}^{-\lambda(\mathrm{t}-\mathrm{h})}-\{\lambda /(\mu-\lambda)\} \mathrm{e}^{-\mu(\mathrm{t}-\mathrm{h})}\right] /\left[\mathrm{h}_{\mathrm{v}}+1 / \mu+1 / \lambda-\{\mu /(\mu-\lambda)\} \mathrm{e}^{-\lambda\left(\mathrm{T}_{1} \mathrm{~h}\right)}-\{\lambda /(\mu-\lambda)\} \mathrm{e}^{-\mu\left(\mathrm{T}_{1}-\mathrm{h}\right)}\right]
\end{gathered}
$$

If $\mathrm{t}>\mathrm{h}$ and distribution function

$$
\begin{gathered}
\left.\mathrm{W}_{\mathrm{T} 1}{ }^{*}(\mathrm{t})=\mathrm{t} /\left[\mathrm{h}_{\mathrm{v}}+1 / \mu+1 / \lambda-\{\mu /(\mu-\lambda)\} \mathrm{e}_{1}^{-\lambda(\mathrm{T}-\mathrm{h})}-\{\lambda /(\mu-\lambda)\} \mathrm{e}^{-\mu(\mathrm{T}}{ }_{1}-\mathrm{h}\right)\right] ; 0<\mathrm{t} \leq \mathrm{h} \\
=\left[\mathrm{h}_{\mathrm{v}}+1 / \mu+1 / \lambda-\{\mu /(\mu-\lambda)\} \mathrm{e}^{-\lambda(\mathrm{t}-\mathrm{h})}-\{\lambda /(\mu-\lambda)\} \mathrm{e}^{-\mu(\mathrm{t}-\mathrm{h})}\right] /\left[\mathrm{h}_{\mathrm{v}}+1 / \mu+1 / \lambda-\{\mu /(\mu-\lambda)\} \mathrm{e}_{1}^{-\lambda(\mathrm{T}-\mathrm{h})}-\{\lambda /(\mu-\lambda)\} \mathrm{e}_{1}^{-\mu\left(\mathrm{T}_{1}-\mathrm{h}\right)}\right] \text { if } \mathrm{t}>\mathrm{h}
\end{gathered}
$$

If $h$ takes $q$ values $h_{1}, h_{2}, \ldots, h_{q}$ with respective proportions of females $b_{1}, b_{2}, \ldots b_{q}$ the probability density function and corresponding distribution extend to

$$
\begin{aligned}
& \mathrm{w}_{\mathrm{T} 1} * *(\mathrm{t})=\sum \mathrm{b}_{\mathrm{v}} \mathrm{w}\left(\mathrm{t} / \mathrm{h}=\mathrm{h}_{\mathrm{v}}\right) ; \mathrm{v}=1,2, \ldots, \mathrm{q} \\
& \mathrm{W}_{\mathrm{T} 1}^{* *}(\mathrm{t})=\sum \mathrm{b}_{\mathrm{v}} \mathrm{W}\left(\mathrm{t} / \mathrm{h}=\mathrm{h}_{\mathrm{v}}\right) ; \mathrm{v}=1,2, \ldots, \mathrm{q}
\end{aligned}
$$

\section{Application}

The application of the derived model on real observed data taken from Demographic Survey of Varanasi Rural, India. In the observed distributions of forward birth interval to females is larger marital duration. Further, to avoid the possible incidence of sterility and heterogeneity in the fertility characteristics females with marital duration 10 to 20 years have been included. As a close approximation in the estimates for the present surveyed population we have taken four point observed values of PPA eq. 3 months, 6 months, 12 months and 18 months with respective proportion of females $b_{1}=0.25, b_{2}=0.35, b_{3}=0.320$ and $b_{4}=0.080$, such that $\sum b_{v}=1$. Further, gestation period $g$ is taken as 9 months $\left(\mathrm{h}_{1}=1.00, \mathrm{~h}_{2}=1.25, \mathrm{~h}_{3}=1.75\right.$, and $\left.\mathrm{h}_{4}=2.25\right)$. The remaining two parameters of the model $\lambda$ and $\mu$ are estimated. The maximum likelihood estimate of the parameters may be computed by using the method of scoring. The maximum likelihood estimates are obtained by solving through matrix equation and variance and covariance of the estimates $(\lambda$ and $\mu)$ were also calculated [9]. The maximum likelihood estimates of the parameters were obtained through matrix equation with the help of BASIC language programmes developed and the calculations were done on personal computer.

\section{Results}

The estimated values of $\lambda$ and $\mu$ are 1.1051 and 2.841 respectively. The variance of estimated $\lambda$ and $\mu$ are 0.067 and 0.79 respectively. The co-variance in between estimated values of $\lambda$ and $\mu$ is -0.026 . With these estimates the expected frequencies for the distribution and $\chi^{2}=0.6057$ is highly significant. Therefore, conclude that the derived model describes the real situations and provides the better estimate. The estimate of $\lambda$ is almost same as compared to the estimates obtained from the data on closed birth interval [14]. The estimates of $\lambda$ and $\mu$ (1.1051 and 2.841) which is also almost same as compared to the estimates obtained from the data on open birth interval (1.0507) and straddling birth interval 1.0559 [9]. These above mentioned estimates have considered and based on the rate of entrance into the state of exposure after the termination of PPA. With these estimates the expected frequencies for the distribution and $\chi^{2}=0.6057$ is highly significant. Thus, the derived probability model explains the fertility behavior of observed data satisfactorily well. 


\section{Summary and Conclusion}

Human fertility behavior is responsible for population growth and it is also for infant mortality. These factors are highly responsible for development of nation and puts extra pressure on economy of nation. Cognizant of these inherent problems, researcher, scientist and demographers have given high priority to a thorough understanding of the differential and determinants of fertility through mathematical and statistical methodologies. Research investigation with the appropriate research models provides the unbiased estimates of parameters through standardized statistical techniques. In recent years more attention is accorded to the analysis of data on birth intervals through analytical models based on realistic assumptions. The usefulness of birth intervals in measuring and describing the levels and changes in fertility is being increasingly recognized by demographers as well as health researchers and provides the better estimates and real picture for better health management and future planning.

The estimate of fecundability $(\lambda)$ obtained by Mishra, 1983 were quite low as compared to estimates of Western countries probably due to the various social and cultural factors affecting human fertility in the rural parts of India viz., the frequent visits to females to their parents in their early marital life, practices of prolonged lactation, joint family system and various other social taboos and rituals[19-22].The estimate of $\lambda$ is quite high compared to estimates obtained previous estimate $\lambda=0.79$ and in another research study $\lambda=0.78[19,23,24]$. The previous studies as mentioned above have not considered the rate of entrance into the state of exposure after the termination of PPA. The high estimate of $\lambda$ is may be due to improvement in the standard of living and also as an impact of urbanization. Further, with passage of time probably role of social customs and rituals has declined in three decades. Therefore, derived model is explained in better manner and provides the estimates of the parameters. The high estimate $\mu$ (2.841) gives that almost all females are exposed to the risk of conception within a year after the termination of PPA and also indicating the role of socio cultural and contraceptive practices for very short period after termination of PPA. This estimated value of $\mu$ indirectly indicates the insignificant impact of birth spacing methods. The same estimated value obtained of through open birth interval[9]. The present described model and results relates to some factors of human reproduction and compared with another estimates obtained through analytical birth interval models which take account of a few factors. It is difficult to cover all the associated factors of human fertility behavior. However, the present derived model can explain and gives the better understanding of change in complex human fertility behavior. Derived model also helps to assessing the real impact of family planning programmes and their effectiveness. Srivastava (1989), Bhardwaj (1989) reported same pattern and Singh (2014) also reported same trend of fecundability and females are expose to the risk of conception at different point through stochastic model of fecundability in between two successive live births (Closed
Birth Interval) and stated that almost all females are exposed to the risk of conception within a year after termination of PPA [14, 25, 26]. Thus, the derived probability model explains the fertility behavior of observed data satisfactorily well and derived model will also help to the researcher for unbiased estimation of risk of conception.

\section{Acknowledgement}

Words fail to me express my deep sense of gratitude to my venerable preceptor Prof. R. N. Mishra, Division of Biostatistics, Department of Community Medicine, Institute of Medical Sciences, BHU, India. I owe special debt of gratitude to Prof. M. B. Masuku, Department of AEM, University of Swaziland, Swaziland, for his valuable suggestions. Lastly, thanks to my family members for their affectionate help and moral support.

\section{References}

[1] Freedman, R., "Expected family size and family size value in West Germany”, Population Studies, 13; 136, 159.

[2] Lenski, G., "The religious factor, Anchor Books", Doubleday, New York, USA, 1963.

[3] Goldberg, D., "Some observations on recent changes in American fertility based on sample survey data", Eugenics Quarterly, 14(4), 255, 1967

[4] Gini, C., "Premieres researches sur la fecundabilite de la femme", Proceedings of the International Mathematics Congress, Toronto, 889-892, 1924.

[5] Sheps, M. C., "Pregnancy wastage as a factor in the analysis of fertility data", Demography, 1, 111-118, 1964.

[6] Singh, S. N.,"Some probability distributions utilized in human fertility", Seminar volume in statistics, BHU, Varanasi, India, p.74, 1966.

[7] Bhattacharya, B.N., C. M. Pandey and K. K. Singh, "Model for closed birth interval and some social factors", Janasankhya, $6(1) ; 57,1988$

[8] Singh, U., "Fertility analysis through birth interval models", unpublished Ph.D. Thesis, Banaras Hindu University, Varanasi, India, 1988.

[9] Singh, A.S., "Some analytical models for human fertility and their applications", unpublished Ph.D. Thesis, Institute of Medical Sciences, BHU, Varanasi, India, 1992.

[10] Mturi, A. J., "The determinants of birth intervals among non contracepting Tanzanin women", African Population Studies, 12(2), 1997.

[11] Rama Rao S., T. John and A. Ian, "Correlates of inter birth intervals: Implications of optional birth spacing strategies in Mozambique", Population Council, 1-17, 2006.

[12] Singh S.N., S. N. Singh and R. K. Narendra, "Demographic and socio-economic determinants of birth interval dynamics in Manipur: A survival analysis", Online Journal of Health and Allied Sciences, 9(4), 2011. 
[13] Yadav R.C., A. Kumar A. and M. Pratap,"Estimation of parity progression ratios from open and closed birth interval, Journal of Data Science, 11, 607-621, 2013.

[14] Singh, A. S., "Stochastic model for estimation of fecundability in between two successive live births (Closed Birth Interval)", Presented in 3 International Science Congress, India, Published in Recent Jr. Research Sciences, 3 (ISC-2013), 1-3, 2014.

[15] Cox, D. R., "Renewal Theory", Methuen and Company Ltd., London, UK, 1962.

[16] Cox, D. R. and H. D. Miller, "The theory of stochastic process', Methuen Co. Ltd., London, UK, 1965.

[17] Pathak, K. B. and A. Pandey, A., "Stochastic models of human reproduction", Himalya Publishing House, Bombay, India, 1993.

[18] Singh, V.K. and O. P. Singh, O.P., "On some probability distributions for forward birth interval", Mathematical Population Studies, 3(2), 145-153, 1991.

[19] Mishra, R. N.,"Some stochastic models and their utility to describe birth interval data", unpublished $\mathrm{Ph}$. D. Thesis, Department of Mathematics and Statistics, Faculty of Science, Banaras Hindu University, India, 1983.
[20] James, W.H., "The fecundability of US women", Population Studies, 27, p. 493, 1973.

[21] Bongarts, J., A method for the estimation of fecundability, Demography, 12, p. 645, 1975.

[22] Bongarts,J. and R. G. Potter, "Fertility, Biology and Behavior ; An analysis of the proximate determinants", Academic Press, new York, USA, 1983.

[23] Singh, S. N., R. C. Yadav and A. Pandey, "On a generalized distribution of open birth interval regardless of parity, Journal of Scientific Research, BHU, India, (1979)

[24] Singh, S. N., A. Pandey and R. N. Mishra, "A generalized probability distribution for open birth interval, The Aligarh Journal of Statistics, 1 (2), p. 183, 1981.

[25] Srivastava, P. K., Ph. D. (Statistics-Preventive and Social Medicine) unpublished thesis, Institute of Medical Sciences, Banaras Hindu University, India, 1992.

[26] Bhardwaj, S. D., Ph. D. (Statistics-Preventive and Social Medicine) unpublished thesis, Institute of Medical Sciences, Thesis, Banaras Hindu University, India, 1992. 